\title{
PARTNERTRALISTIC SUPERVISION APPROACH TO IMPROVING THE QUALITY OF BASIC EDUCATION
}

\author{
Ahmad Sulhan \\ Universitas Islam Negeri Mataram, Lombok, Nusa Tenggara Barat \\ Email: ahmadsulhan@gmail.com \\ Mohammad Viktor Farid Hakim \\ Universitas Islam Negeri Mataram, Lombok, Nusa Tenggara Barat \\ Email: viktorfaridhakim@gmail.com \\ DOI: 10.35445/alishlah.v12.i2.288 \\ Accepted: November $28^{\text {th }}, 2020$. Approved: December $20^{\text {th }}, 2020$ \\ Published: December $30^{\text {th }}, 2020$
}

\begin{abstract}
The research objective was to obtain a partnership concept in the supervision activities at SDIT Anak Sholeh Mataram in order to improve the quality of education. Basically, supervision activities are not only routine evaluations of educational activities. The research method used qualitative with case studies. Data collection techniques used observation, interviews, and documentation. The data analysis technique consists of three stages, namely data reduction, data presentation, and drawing conclusions. The results showed that a partnertralistic form of supervision at SDIT Anak Sholeh Mataram was evident from the involvement of parents, teachers, school principals, school committees, and class forums in various educational activities. This has implications for developing intense communication with all parties in increasing educational activities in schools.
\end{abstract}

Keywords: Partnertralistik, Basic Education, Supervision

\section{PENDEKATAN SUPERVISI PARTNERTRALISTIK DALAM MENINGKATKAN KUALITAS PENDIDIKAN DASAR}

\begin{abstract}
Abstrak
Tujuan penelitian adalah untuk mendapatkan konsep kemitraan dalam kegiatan supervisi di SDIT Anak Sholeh Mataram dalam rangka meningkatkan kualitas pendidikan. Pada dasarnya kegiatan supervisi tidak hanya menjadi rutinitas evaluasi terhadap aktivitas penyelenggaraan pendidikan. Metode penelitian menggunakan kualitatif dengan studi kasus. Teknik pengumpulan data menggunakan observasi, wawancara, dan dokumentasi. Teknik analisis data terdiri dari tiga tahap yaitu reduksi data, penyajian data, dan penarikan
\end{abstract}


Al-Ishlah: Jurnal Pendidikan - ISSN: 2087-949o (p); 2597-940X (e)

Vol. 12, No. 2 (2020)

simpulan. Hasil penelitian menunjukkan bahwa bentuk partnertralistik dalam kegiatan supervisi di SDIT Anak Sholeh Mataram terlihat dari keterlibatan para orang tua, guru, kepala sekolah, komite sekolah, dan forum kelas dalam berbagai aktivitas penyelenggaraan pendidikan. Hal ini berimplikasi pada pengembangan komunikasi yang intens terhadap semua pihak dalam meningkatkan kegiatan pendidikan di sekolah.

Kata Kunci: Partnertralistik, Pendidikan Dasar, Supervisi

\section{PENDAHULUAN}

Peningkatan kualitas pendidikan melalui program supervisi menjadi tanggung jawab untuk mencapai setiap tujuan yang telah dirancang. Apalagi saat ini, dunia pendidikan di Indonesia harus mampu menciptakan proses pendidikan yang memiliki keseimbangan dengan kebutuhan global. Dengan demikian, supervisi menjadi salah satu solusi untuk menciptakan program pendidikan yang bermutu. Supervisi dalam pendidikan bukan hanya sekadar kontrol melihat apakah segala kegiatan telah dilaksanakan sesuai dengan rencana atau program yang telah digariskan, tetapi lebih dari itu. Supervisi yang baik mengarahkan perhatiannya kepada dasar-dasar pendidikan dan cara-cara belajar serta perkembangannya dalam pencapaian tujuan umum pendidikan

Oleh karena itu, kegiatan supervisi dilakukan dengan berbagai pendekatan. Salah satu pendekatan supervisi yang banyak dilakukan adalah pendekatan bermitra atau partnership. Konsep supervisi partnership atau dikenal dengan sebutan bermitra merujuk pada kegiatan supervisi yang melibatkan pihak luar untuk melakukan kegiatan penilaian terhadap penyelenggaraan pendidikan. Di SDIT Anak Sholeh Mataram juga melakukan kegiatan supervisi secara rutin untuk meningkatkan kualitas pendidikan. Hal ini dilakukan karena SDIT Anak Sholeh masih menghadapi permasalahan dalam peningkatan penyelenggaraan pendidikan. Permasalahan tersebut tidak hanya berkaitan dengan kurikulum, akan tetapi aspek lain seperti sumber daya pendidik, sumber keuangan, metode pembelajaran, dan sebagainya masih belum memenuhi kebutuhan penyelenggaraan pendidikan. Apalagi, era global menuntut penyelenggaraan pendidikan yang bisa relevan dengan berbagai perubahan yang begitu cepat baik pada aspek keilmuan ataupun teknologi. Hal ini berkaitan dengan perkembangan kebutuhan dunia industri dan dunia usaha.

Salah satu cara yang bisa dilakukan adalah evaluasi terhadap berbagai aktivitas penyelenggaraan pendidikan di SDIT Anak Sholeh yaitu supervisi. Banyak penelitian terdahulu yang telah dilakukan berkaitan dengan supervisi. Supervisi yang telah dilakukan dengan efektif bisa meningkatkan mutu pembelajaran, seperti pendekatan kolaboratif yang melibatkan pihak lain dalam peningkatan kualitas pendidikan (Dwikurnaningsih, 2019). Salah satu kegiatan supervisi dilakukan pengawas sekolah sesuai dengan aturan yang berlaku 
Vol. 12, No. 2 (2020)

(Chudzaifah, 2020). Kegiatan supervisi dilaksanakan dalam tiga tahap yaitu perencanaan, pelaksanaan dan pelaporan dengan berbagai macam teknik (Ghufron \& Mubarok, 2018), misalkan kunjungan kelas, atau pengamatan (observasi) kelas, dan sebagainya (Ariasa Giri, 2016). Teknik supervisi mentoring dapat membangun keakraban antara para pengawas dan guru (Masliah, 2019). Jadi, fungsi supervisi yang dilakukan oleh kepala sekolah bisa memberikan motivasi dalam meningkatkan kualitas pendidikan (Hajeni, Kadir, \& Hakim, 2020). Oleh karena itu, model supervisi harus dikembangkan sesuai dengan kebutuhan di lapangan (Rasto \& Mulyani, 2017). Salah satu contohnya adalah supervisi klinis membantu para guru meningkatkan keterampilan mengajar di kelas (Humairoh, Supriyanto, \& Burhanuddin, 2016). Dengan demikian, supervisi menjadi salah satu media yang bisa meningkatkan profesionalisme guru dan melakukan pemecahan masalah pengajaran (Maralih, 2014).

Dari paparan penelitian terdahulu fokus pada peningkatan kualitas pendidikan. Oleh karena itu, penelitian ini lebih diarahkan pada implementasi pendekatan bermitra dalam meningkatkan pendidikan sekolah dasar di Mataram. Hal ini perlu dilakukan karena beberapa alasan antara lain; 1) supervisi bisa memberikan kontribusi dalam mengembangkan mutu pendidikan di era globalisasi, 2) supervisi dengan pendekatan bermitra dapat memenuhi kebutuhan masukan terhadap penyelenggaraan pendidikan, dan 3) kegiatan supervisi menjadi alternatif pemecahan masalah penyelenggaraan pendidikan. Penelitian ini bisa memberikan kontribusi terhadap pendekatan partnership untuk mengetahui hubungan mitra sekolah dalam pengembangan kualitas pendidikan.

Supervisi pendidikan merupakan proses formal untuk menyelesaikan masalah. Hal ini bertujuan memberikan panduan dan timbal balik terhadap proses pendidikan. Supervisi pendidikan telah menjadi sangat dibutuhkan saat ini karena proses pendidikan dan keinginan untuk meningkatkan kualitas pendidikan. Jadi supervisi dirancang unutk memberikan perubahan dalam pengajaran, pemecahan masalah sekolah, membangun kerjasama, meningkatkan motivasi intinsik para staf sekolah. Selain itu juga, supervisi memberikan kesempatan untuk menghadapi tantangan yang dimiliki sekolah dan mencapai tujuan sekolah.

Dengan demikian, tujuan penelitian ini adalah untuk mengetahui pendekatan partnership yang digunakan untuk meningkatkan pendidikan dasar di SDIT Anak Sholeh Mataram. Partnership atau bermitra bertumpu pada orang yang disupervisi sebagai supervisor, pemahaman tujuan dan proses supervisi, dan persfektif peran atau tanggung jawab. Konsep bermitra tersebut telah membangun peran supervisor untuk mengajari atau memandu orang yang disupervisi tentang supervisi. Maka bermitra atau berpartner harus saling berkonsolidasi, mekanisme kerja bersama telah dirancang dan pendekatan harus dikembangkan untuk 
Al-Ishlah: Jurnal Pendidikan - ISSN: 2087-949o (p); 2597-940X (e)

Vol. 12, No. 2 (2020)

membangun kerja baik dalam jaringan lokal maupun regional, yang bergantung pada suatu kondisi.

Penelitian ini akan dapat memberikan kontribusi terhadap pengembangan keilmuan pendekatan supervisi agar relevan dengan perkembangan tuntutan global saat ini. Proses supervisi pendidikan dapat dilakukan dengan berbagai macam pendekatan. Pendekatan partnership adalah pendekatan kemitraan yang dibangun atas dasar kebutuhan. Sedangkan pendekatan terakhir adalah pendekatan interaktif yaitu pendekatan supervisi yang bersifat komunikatif. Setiap mitra dapat membawa pengetahuan dan keterampilan yang bisa dibagikan kepada orang lain.

\section{METODE PENELITIAN}

Penelitian ini menggunakan metode kualitatif dengan rancangan studi kasus. Penelitian kualitatif merupakan suatu penyelidikan dan memahami fenomena sosial yang dilakukan sesuai pada fakta yang terjadi (Ary, Jacobs, Sorensen, \& Razavieh, 2010). Jadi, penelitian ini dilakukan melalui proses penggalian informasi yang terjadi di lapangan. Kegiatan penelitian dilakukan di SDIT Anak Sholeh Mataram di Jl. Merdeka Raya Merdeka VII atau Gg. Anak Sholeh School Pagesangan Mataram. Teknik pengumpulan data menggunakan observasi, wawancara dan dokumentasi. Observasi dilakukan melalui pengamatan langsung dengan datang ke sekolah mengamati berbagai fenomena yang terjadi di sekolah. Wawancara dilakukan dengan kepada sekolah, ketua forum kelas, sekretaris forum kelas, guru, dan perwakilan komite sekolah. Dokumentasi diambil dari dokumen sekolah yang berkaitan dengan fokus masalah. Teknik analisis data merujuk pada model Miles dan Huberman (Miles \& Huberman, 1994) sebagai berikut; 1) Reduksi data digunakan untuk menelaah data yang telah terkumpul untuk disesuaikan dengan kebutuhan fokus penelitian. 2) Penyajian data dilakukan dengan cara mengklasifikasikan data sesuai pada kategori fokus masalah. 3) Kesimpulan dan verifikasi yaitu mengklarifikasi data dan mengorganisasikan data untuk dianalisis sehingga diperoleh jawaban fokus penelitian.

\section{HASIL DAN PEMBAHASAN}

Kesuksesan pendidikan tidaklah hanya diukur dari kualitas gedung dan mahalnya biaya, tetapi lebih dapat dirasakan dari apa yang diterima oleh anakanak agar mereka bisa tumbuh sesuai dengan potensi yang dimiliki dan berkembang sejalan dengan tuntunan agama. Karenanya, kehadiran sekolah tidak hanya ditujukan untuk mengembangkan potensi akademik semata tetapi juga melejitkan potensi-potensi kepemimpinan, kewirausahaan, dan kemandirian yang terbingkai dalam religiusitas, kedekatan dengan nilai agama. Pengembangan potensi-potensi tersebut dilaksanakan oleh SDIT Anak Sholeh Mataram dalam suasana sekolah bernuansa alam dengan harapan anak-anak dapat secara optimal mengembangkan dirinya selaras dengan tempat dimana ia berada. 
Beberapa hal hasil supervisi pada penyelenggaraan pendidikan di SDIT Anak Sholeh yang sesuai dengan pendekatan partnership adalah;

1. Kurikulum

Kurikulum Tingkat Satuan Pendidikan Sekolah Dasar SD Islam Terpadu Anak Sholeh dikembangkan sebagai perwujudan dari kurikulum pendidikan dasar dan menengah. Kurikulum ini disusun oleh satu tim penyusun yang terdiri atas unsur sekolah dan komite sekolah dibawah koordinasi dan supervisi YPIT Ibnu Abbas Mataram yang didasarkan pada prinsip-prinsip sebagai berikut:

a) kepentingan nasional berpusat pada potensi, perkembangan, kebutuhan, dan kepentingan peserta didik dan lingkungannya;

b) beragam dan terpadu;

c) tanggap terhadap perkembangan ilmu pengetahuan, teknologi dan seni;

d) relevan dengan kebutuhan kehidupan;

e) menyeluruh dan berkesinambungan;

f) belajar sepanjang hayat; dan

g) seimbang antara dan kepentingan daerah.

Dari prinsip-prinsip diatas lalu dijabarkan sesuai dengan visi dan misi yang ingin dikembangkan oleh SD Islam Terpadu Anak Sholeh Mataram sehingga kurikulum tersebut diarahkan menjadi :

a) kurikulum yang mengembangkan kecerdasan (Bahasa, Sains, logika matematika);

b) kurikulum yang mengembangkan kreativitas (Outbound, pendidikan jasmani, kewirausahaan, seni, kepanduan, dan sosial kemasyarakatan); dan

c) kurikulum yang mengembangkan ketaqwaan (keimanan, ibadah, Al-Quran, sikap hidup, dan integrasi dengan alam).

2. Penentuan kebijakan

Pelaksanakan sebuah kebijakan tentunya lebih sulit dari hanya memutuskan kebijakan. Pelaksanaan kebijakan yang menjadi kesepakatan bersama perlu diiringi dengan kontrol maupun masukan. Peran ini dilakukan dengan baik oleh komite sekolah. Kepala sekolah menambahkan bahwa komite sekolah dalam berbagai kegiatan selalu aktif dan pelaksanaan kebijakan yang dijalankan sekolah dievaluasi sehingga ketika dijumpai permasalahan, mereka melalukan musyawarah dengan anggota lainnya untuk dicari solusinya, setelah itu mereka menyampaikan kepada pihak sekolah. Keterlibatan komite sekolah sangat aktif dan berkesinambungan dalam memberikan berbagai masukan yang sifatnya membangun serta disampaikan secara arif dan bijaksana baik dalam forum resmi atau formal atau pada setiap kegiatan yang diadakan.

Selanjutnya, Ketua Forum Kelas menjelaskan biasanya ada pertemuan rutin setiap bulan antara sekolah dan komite, disitulah saran-saran disampaikan. Pengurus forum-forum kelas menjelaskan bahwa, komite belum pernah 
Vol. 12, No. 2 (2020)

memberikan pertimbangan dalam penentuan kebijakan. Selama ini penentuan kebijakan masih diputuskan oleh pihak sekolah. Dalam hal ini forum guru ynag telah di bentuk merupakan wahana yang tersedia antar guru dalam masing-masing kelas, dari sini pula terbentuk sebuah kesepakatan dan pada akhirnya diajukan oleh forum kepada tatanan yang lebih tinggi yakni pada rapat penentuan policy di kalangan pemangku jabatan mulai pengurus yayasan, komite sekolah dan seluruh anggota keluarga sekolah. Dalam kegiatan ini dilihat berbagai pandangan dan pertimbangan bagian mana yang harus ditolak maupun diterima oleh forum yang lebih tinggi.

3. Pengembangan kondisi finansial

Komite di SDIT Anak Sholeh melakukan inisiatif-inisiatif melalui perwakilan-perwakilan di masing-masing kelas. Perwakilan tersebut disebut koordinator kelas yang bertugas untuk memantau proses pembelajaran terdapat kendala yang dihadapi, untuk mengantisipasi kendala yang mungkin terjadi. Koordinator kelas ini mengeluarkan iuran. Iuran tersebut dipergunakan untuk kebutuhan masing-masing kelas demi kelancaran pembelajarannya. Kepala Sekolah menjelaskan bahwa komite sekolah dalam proses pembelajaran selain SPP setiap bulannya, komite memiliki perwakilan di masing-masing kelas. Perwakilan ini disebut koordinator kelas.

Koordinator kelas berfungsi melihat proses pembelajaran berjalan dengan baik atau terbentur kendala. Untuk itu, mereka mengeluarkan iuran untuk menanggulangi kendala tersebut, nantinya uang tersebut digunakan untuk kebutuhan masing-masing kelas seperti air minum dan spidol. Bendahara forum kelas III memberikan penjelasan, komite sangat mendukung penyelenggaraan pendidikan karena tiap bulan kita ada iuran untuk kegiatan. Sesuai dengan penjelasan yang didapatkan dari pihak sekolah maupun perwakilan komite di kelas-kelas, nampak dukungan komite secara finansial sangat tinggi. Komite mengeluarkan iuran yang nantinya iuran tersebut dipergunakan untuk kelancaran pembelajaran dan untuk menanggulangi kekurangan yang mungkin ada ketika pembelajaran dilakukan.

Disamping support finansial, peran komite juga berperan dalam menyumbangkan pemikiran dalam meningkatkan kualitas pembelajaran maupun dalam proses pembelajaran sehingga dapat berjalan dengan efektif. Sejalan dengan hal tersebut, ketua forum kelas menjelaskan, dukungan pemikiran full support karena komite rata-rata isinya perwakilan forum kelas. Jadi secara otomatis dukungan-dukungan diberikan untuk kegiatan pembelajaran. Komite memberikan ide-ide, gagasan, tetapi keputusan tetap menjadi hak sekolah.

Dukungan tenaga sebagai bagian dari peran komite ternyata juga selalu diberikan oleh komite apabila dibutuhkan. Sebagai gambaran, sebagian besar anggota komite adalahguru yang menjadi pengurus kelas.Setiap saat mereka ikut 
Vol. 12, No. 2 (2020)

berpartisipasi dalam kegiatan pembelajaran, begitu juga komite yang tidak terlibat langsung di kelas.Mereka selalu memberikan dukungan terutama dalam berbagai kegiatan sepertipenyembelihan hewan korban juga pada hari-hari besar Islam. Pengurus kelas menjelaskan, "Dukungan tenaga diberikan setiap diperlukan oleh sekolah misalnya dalam acara penyembelihan hewan korban." Ketua forum kelas 2 juga memberikan tanggapan bahwa dukungan tenaga sudah pasti karena sering kali ada kegiatan sekolah melibatkan komite, dalam konteks saling membantu antara semua anggota yang mengganggap diri sebuah keluarga yang tetap mempertahankan romantik kekeluaragaan dan lebih mementingkan keadaan sosial yang saling bekerja sama bukan hasil yang menjadi ukuran utama .

4. Transparansi, Akuntabilitas, Keluaran

Transparansi pengelolaan pendidikan di SDIT Anak Sholeh senantiasa ditunjukkan oleh pihak sekolah baik kepada komite maupun Yayasan. Kontrol mengenai transparansi pengelolaan pendidikan di SDIT dimulai dari para guru, ustaz, ustazah di sekolah kemudian kontrol juga dilakukan ke sekolah. Perlu diketahui bahwa istilah yang digunakan pada sekolah ini ketika memanggil guru oleh peserta didik adalah ustaz dan ustazah yang agak berbeda pada sekolahsekolah yang ada di kota mataram.

Diperlukan partisipasi bersama antar seluruh kalangan masyarakat yang menjadikannya tetap kokoh sebagai kesatuan dalam bingkai mainstones yang sudah menjadi tradisi antar orang tua siswa atau santri dalam istilah SDIT. Selanjutnya, ditambahkan pula Sugiarti, kontrol transparansi pendidikan dilakukan oleh komite dan sekolah telah menyampaikan laporan-laporan. Kontrol seperti diatas sudah menjadi kebiasaan antar semua kalangan bukan hanya menjadi tanggungjawab pihak komite yang di amanahkan oleh orang tua dan yayasan, tetapi menjadi kekuatan yang holistic sehingga orang tua pula ikut mengambil peran demi kemajuan bersama.

Komite selalu ikut melakukan kontrol melalui wali kelas atau ke pihak sekolah langsung. Disisi lain komite menempatkan dirinya sebagai pewawancara yang handal untuk menggali informasi yang lebih akurat, bukan hanya mendengarkan penjelasan dari pihak sekolah tapi orang tua yang merasakan secara langsung atau progress dari sekolah tempat mereka menitipkan anaknya. Melalui orang tua yang memberikan amanah sepenuhnya untuk menyekolahkan anak-anak mereka untuk tetap memberikan the exellent of service. Dengan demikian, dapat mengurangi kecurangan yang mungkin muncul pada kalangan orang tua wali di SDIT Anak Soleh.

\section{Kontrol Akuntabilitas}

Akuntabilitas adalah bentuk pertanggungjawaban pengelolaan pendidikan yang dilakukan oleh SDIT Anak Soleh di pandang rasional oleh orang tua. Ada anggapan bahwa unsur pembentuk keberhasilan utama adalah sistem manajemen 
Vol. 12, No. 2 (2020)

yang mampu menunjukkan kinerja terbaik sekolah dalam bentuk akuntabel. Dalam hal ini akuntabilitas dimaknai sebagai proses pendidikan yang dilakukan oleh SDIT dapat dipertanggungjawabkan kebenarannya. Agar hal ini tetap terjaga, peran komite dan pengawas sangat penting untuk melaksanakan fungsi kontrolingnya.

1) Implementasi Kontrol Akuntabilitas. Sistem kontrol (sistem kendali) telah memegang peranan yang sangat penting dalam perkembangan ilmu dan teknologi. Di samping sangat diperlukan pada pesawat ruang sekolah, peluru kendali (komite sekolah), dan sistem kemudi navigator yakni kepala sekolah. Berbagai macam sistem kontrol juga menjadi bagian yang penting dan terpadu dari proses - proses dalam pembentuk dan karakteristik modern yang bermuatan islami. Penanganan yang tanggap dan praktisasi pengajaran yang harus di lakukan oleh SDIT Anak Soleh Mataram karena kemajuan dalam teori dan praktek sistem kontrol keuangan, maka sistem kontrol dapat memberikan kemudahan dalam mendapatkan formasi dari sistem dinamik, mempertinggi kualitas dan menurunkan biaya produksi, mempertinggi laju produksi, meniadakan pekerjaan atau job rutin yang harus dilakukan oleh manusia untuk mengetahui keadaan keuangan yang di miliki oleh sekolah. Pengertian sistem kontrol itu sendiri adalah proses pengaturan / pengendalian terhadap satu buah sistem sekolah, sehingga berada pada suatu value atau rangkuman harga (range) terhadap pendidikan tertentu. Oleh karena itu, proses-proses yang telah ada menjadikan sekolah SDIT Anak Sholeh memiliki sistem kontrol yang kokoh. Menurut Ketua Forum Kelas bahwasanya hal ini penting untuk terus dilanjukan karena bentuk kontrol terhadap keluaran. Semua anggaran yang sudah digunakan dan dibelanjakan sudah ada terpampang pada papan pengumuman orang tua dan orang tua tidak khawatir atas uang yang telah dikeluarkan untuk membiayai proses pendidikan anak mereka.

2) Kerjasama antara Masyarakat dan Pemerintah. Sebuah lembaga pendidikan tidak bisa berdiri sendiri tanpa melakukan kerja sama atau hubungan yang baik dengan pemerintah atau masyarakat, hubungan dengan pemerintah berkaitan dengan kebijakan-kebijakan maupun bantuan lainnya, begitu juga kerjasama dengan masyarakat terkait dengan dukungan dan partisipasi masyarakat untuk menyokong pembelajaran yang dilakukan agar tetap berjalan dengan efektif. Beberapa kerjasama yang dilakukan dengan masyrakat dalam bentuk bakti sosial. Penjelasan senada juga disampaikan oleh anggota komite, komite melakukan kerjasama dengan masyarakat sekitar/ perusahaan-perusahaan yang ada untuk pendidikan. Komite sering melakukan kerjasama dengan masyarakat dalam bentuk baksos dan kunjungan ke panti asuhan. Adapun kerjasama dengan pemerintah juga dilakukan dengan baik 
Vol. 12, No. 2 (2020)

misalkan untuk perbaikan sarana dan prasarana, komite dan sekolah juga menjalin kerjasama dengan Dinas PU dalam melakukan perbaikan jalan.

3) Menampung dan menganalisis aspirasi, ide, tuntutan, dan kebutuhan masyarakan. Fungsi menampung dan menganalisis aspirasi dari masyarakat tentunya harus dijalankan dengan baik oleh sekolah, ataupun komite. Keberadaan komite berimplikasi positif bagi sekolah dan masyarakat. Ketua Forum Kelas menjelaskan bahwa aspirasi dari masyarakat komite tampung dan lanjutkan ke pihak sekolah. Untuk menjalankan fungsi menampung dan analisis aspirasi ini, mekanisme yang dilakukan sekolah dan komite melalui rapat, akan tetapi apabila menyangkut persoalan eksternal biasanya melalui rapat yang diselenggarakan secara bersama-sama dengan seluruh komite, yayasan, kepala sekolah, dan lain-lain.

Supervisi mencakup arti yang terkandung dalam beberapa istilah seperti inspeksi, penilikan atau pengawasan, dan evaluasi. Jika dikaitkan dengan UU No 20 Tahun 2003 maka jelas istilah-istilah tersebut sangat berhubungan. Oleh karena itu, mitra merupakan bagian yang tidak bisa dipisahkan dari kegiatan supervisi untuk mengevaluasi penyelenggaraan pendidikan di sekolah agar peran kepala sekolah yang sering menjadi supervisor tidak tumpang tindih dalam melaksanakan evaluasi (Handayani \& Sukirman, 2020). Hasil supervisi menjadi pedoman yang sangat baik untuk memberikan masukan terhadap berbagai aktvitas yang dilakukan di sekolah terkait dengan mutu, seperti aspek apersepsi dan motivasi dalam pembelajaran (Saleh, 2019). Selain itu, kolaborasi dalam supervisi akademik memberikan layanan dan pembinaan yang sistematis (Jamila, 2020).

Di era global saat ini, kegiatan supervisi juga bisa memanfaatkan sistem informasi dalam mendukung perbaikan kegiatan pembelajaran dan pengajaran di sekolah (Indadihayati, 2020; Andani, Yulianto, \& Murwatiningsih, 2017). Supervisi dalam pendidikan bukan hanya sekadar kontrol melihat apakah segala kegiatan telah dilaksanakan sesuai dengan rencana atau program yang telah digariskan, tetapi lebih dari itu. Kegiatan supervisi mencakup penentuan kondisikondisi atau syarat-syarat personel maupun material yang diperlukan untuk terciptanya situasi belajar-rnengajar yang efektif, dan usaha memenuhi syaratsyarat itu.

\section{SIMPULAN}

Hasil analisis data menunjukkan bahwa pendekatan partnership yang digunakan di SDIT Anak Sholeh Mataram terlihat pada keterlibatan komite sekolah, masyarakat, pemerintah, guru, kepala sekolah, dan forum kelas dalam melaksanakan kegiatan penyelenggaraan pendidikan. Selain itu, pengawasan dari komite sekolah sangat membantu penyelenggaraan kegiatan di sekolah dalam proses pengawasan dan evaluasi. Berbagai permasalahan diselesaikan tidak hanya sesuai keputusan internal sekolah, akan tetapi masukan dari pihak luar juga 
Al-Ishlah: Jurnal Pendidikan - ISSN: 2087-949o (p); 2597-940X (e)

Vol. 12, No. 2 (2020)

dipertimbangkan untuk membuat keputusan. Sekolah juga melakukan keterbukaan berbagai informasi tentang aktivitas penyelenggaraan di sekolah. Hasil penelitian berimplikasi pada pengembangan model supervisi bermitra di sekolah, khususnya untuk SDIT Anak Sholeh. Hal ini bisa memberikan hasil penilaian yang lebih objektif dan sekolah juga dapat berkontribusi terhadap kebutuhan masyarakat akan proses pendidikan bagi anak-anak mereka. Jadi, sekolah menjadi tempat yang mampu memfasilitasi kebutuhan penyelenggaraan pendidikan bagi masyarakat. Namun, selama proses pengumpulan data, penelitian ini memiliki keterbatasan dalam pengumpulan informasi. Oleh karena itu, jika peneliti atau praktisi yang ingin melakukan penelitian tentang supervisi bisa mengembangkan masalah menjadi lebih bervariasi pada seluruh aspek dalam penyelenggaraan pendidikan. Sekolah juga harus tetap membangun komunikasi yang baik dengan berbagai pihak agar kegiatan supervisi ataupun pengawasan penyelenggaraan pendidikan di SDIT tetap terjaga secara kualitas dan objektif dalam memberikan penilaian.

\section{DAFTAR PUSTAKA}

Andani, Y. S. B., Yulianto, A., \& Murwatiningsih. (2017). Model Supervisi Klinis Berbasis Teknologi Informasi dan Komunikasi Untuk Menigkatkan Kinerja Guru Produktif di Smkn 1 Kota Bima. Educational Management, 6(2), 163169.

Ariasa Giri, I. M. (2016). SUPERVISI PENDIDIKAN DALAM PENINGKATAN MUTU PENDIDIKAN DI SEKOLAH. Jurnal Penjaminan Mutu, 2(1), 44. https://doi.org/10.25078/jpm.v2i1.60

Ary, D., Jacobs, L. C., Sorensen, C., \& Razavieh, A. (2010). Introduction to Research in Education (8 Edition). CA: Cengage Learning.

Chudzaifah, I. (2020). Supervisi Pendidikan Islam: Telaah Model Pengawasan Madrasah di Kota Sorong. AL-FIKR: Jurnal Pendidikan Islam, 5(2), 18-30. https://doi.org/10.32489/alfikr.v5i2.23

Dwikurnaningsih, Y. (2019). SUPERVISI AKADEMIK MELALUI PENDEKATAN KOLABORATIF OLEH KEPALA SEKOLAH DALAM MENINGKATKAN KUALITAS PEMBELAJARAN GURU DI SD KABUPATEN GROBOGAN. Satya Widya, 34(2), 101-111. https://doi.org/10.24246/j.sw.2018.v34.i2.p101-111

Ghufron, A., \& Mubarok, H. (2018). SUPERVISI AKADEMIK SEBAGAI DASAR PENGEMBANGAN PEMBELAJARAN GURU. ELEMENTARY, 4(2). https://doi.org/10.21043/elementary.v4i2.3000

Hajeni, H., Kadir, A., \& Hakim, N. (2020). MODEL SUPERVISI AKADEMIK PENGAWAS DALAM MENINGKATKAN KOMPETENSI GURU 
Al-Ishlah: Jurnal Pendidikan - ISSN: 2087-949o (p); 2597-940X (e)

Vol. 12, No. 2 (2020)

TAMAN KANAK-KANAK DI KOTA PALOPO. RESONA : Jurnal Ilmiah Pengabdian Masyarakat, 3(2). https://doi.org/10.35906/resona.v3i2.357

Handayani, L., \& Sukirman. (2020). KONTRIBUSI SUPERVISI KEPALA SEKOLAH PADA PENINGKATAN KUALITAS PEMBELAJARAN DI SMP 3 BAE KUDUS. EduPsyCouns Journal, 2(1).

Humairoh, F., Supriyanto, A., \& Burhanuddin. (2016). Implementasi Supervisi Klinis Dalam Meningkatkan Kualitas Pembelajaran Guru Di Sekolah Dasar. Jurnal Pendidikan: Teori, Penelitian, Dan Pengembangan, 1(12), 22772280 .

Indadihayati, W. (2020). No SISTEM INFORMASI MODEL SUPERVISI KLINIK BERBASIS MANAJEMEN PENGETAHUAN DALAM MENINGKATKAN MUTU PEMBELAJARAN. Jurnal Dinamika Manajemen Pendidikan (JDMP), 4(2).

Jamila. (2020). Pengembangan Model Supervisi Akademik Berbasis Kolaboratif (Studi Pada Pengawas Sekolah Menengah Pertama Dinas Pendidikan Medan). Jurnal Manajemen Pendidikan Dasar, Menengah Dan Tinggi (JMP-DMT), 1(1).

Maralih. (2014). Peranan Supervisi Dalam Peningkatan Kualitas Pendidikan. Jurnal Qathruna, 1(1).

Masliah, E. (2019). Pengembangan Model Supervisi Akademik Teknik Mentoring dalam Upaya Peningkatan Mutu Pembelajaran. Indoensian Journal of Educational Management \& Administration Review, 3(2).

Miles, M. B., \& Huberman, A. M. (1994). Qualitative Data Analysis; An Expanded Sourcebook. New Delhi: Sage Publication.

Rasto, \& Mulyani, H. (2017). Pengembangan Model Supervisi Akademik Untuk Meningkatkan Kualitas Pembelajaran Pada SMK Bidang Keahlian Bisnis dan Manajemen Di Kota Bandung. Jurnal Pendidikan Akuntansi Dan Keuangan, 5(2), 99-106.

Saleh, D. (2019). SUPERVISI AKADEMIK DAPAT MENINGKATKAN KUALITAS PEMBELAJARAN PRODUK KREATIF KEWIRAUSAHAAN DI SMK NEGERI 1 CIMAHI. Jurnal Ilmiah UPT P2M STKIP Siliwangi, 6(2). 